\title{
Pengaruh Store Atmosphere, Kualitas Produk, dan Kualitas Layanan terhadap Kepuasan Konsumen di Seniman Coffee Studio
}

\author{
NI WAYAN GIANA KUSUMAWATHI, DWI PUTRA DARMAWAN \\ I G.A OKA SURYAWARDANI \\ Program Studi Agribisnis Fakultas Pertanian Universitas Udayana \\ Jalan PB Sudirman Denpasar 80232 \\ E-mail: kusumawathigiana@yahoo.com, \\ dwiputradarmawan@yahoo.com
}

\begin{abstract}
Effect of Store Atmosphere, Product Quality, and Service Quality on Consumer Satisfaction at the Seniman Coffee Studio
\end{abstract}

The rapid development of coffee shops in the Ubud sub-district is certainly the main competitors of the Seniman Coffee Studio to attract consumers. This research was conducted to determine the characteristics of consumers of Seniman Coffee Studio and the effect of store atmosphere, product quality, and service quality on consumer satisfaction at Seniman Coffee Studio. This study uses descriptive analysis and analysis of Structural Equation Modeling (SEM) through the Partial Least Squares (PLS) approach. The method of obtaining data in this study was through distributing questionnaires at Seniman Coffee Studio. The results of this study indicate that store atmosphere has a direct effect of $23.8 \%$ on customer satisfaction, product quality has a direct effect of $41 \%$ on customer satisfaction, and for service quality it also has a direct effect of $41.7 \%$ on consumer satisfaction at the Seniman Coffee Studio. Store atmosphere, both exterior and interior, at Seniman Coffee Studio needs to be improved, seeing its effect is smaller than the quality of the product and the quality service on customer satisfaction.

Keywords: store atmosphere, product quality, service quality, consumer satisfaction, structural equation modeling (SEM)

\section{Pendahuluan}

\subsection{Latar Belakang}

Indonesia merupakan negara penghasil kopi terbesar keempat setelah Brazil, Vietnam, dan Kolombia berdasarkan data Kementan tahun (2016). Permintaan akan kopi membuat para wiraswasta tertarik untuk membuka usaha kedai kopi atau coffee shop karena mengkonsumsi minuman seperti kopi telah menjadi salah satu kebutuhan atau gaya hidup (life style) masyarakat saat ini, didasari oleh hal tersebut banyak bermunculan kedai kopi yang membuat persaingan semakin ketat. 
Strategi untuk bersaing dalam usaha kedai kopi yakni harus memperhatikan store atmosphere (suasana ruangan) dalam kedai, kerena semakin nyaman suasana yang diciptakan maka pengunjung akan memutuskan melakukan pembelian ulang jika tingkat kepuasannya terpenuhi, demikian halnya dengan kualitas produk dan kualiats layanan yang baik tentunya akan mempengaruhi kepuasan konsumen yang berkunjung. Menurut Tjiptono (2000) kualitas layanan adalah upaya pemenuhan kebutuhan dan keinginan pelanggan serta ketepatan penyampaiannya untuk mengimbangi harapan pelanggan.

Hasil penelitian Suryawardani (2018) tentang Evaluation of Marketing Strategy of Sanur Village Festival Baesd on Visitors' Behaviour dengan pendekatan The Theory of Planned Behaviour dan dianalisis dengan Smart-PLS menyimpulkan bahwa komunikasi pemasaran secara terintegrasi sudah diterapkan pada event seni budaya yang sangat bergengsi dalam rangka membangkitkan kembali pariwisata Bali setelah terpuruk akibat berbagai kejadian terorisme yang sangat merugikan. Ubud merupakan salah satu destinasi favorit di Bali, dan pada saat ini Ubud memiliki kedai kopi yang mencirikan nilai seni yaitu Seniman Coffee Studio. Fasilitas akomodasi yang ada di Ubud semakin berkembang diiringi dengan pesatnya perkembangan kedai kopi atau coffee shop yang menjadi kompetitor utama Seniman Coffee Studio untuk bersaing menarik konsumen. Pesatnya peningkatan kedai kopi atau coffee shop di Kecamatan Ubud berimplikasi pada peningkatan persaingan yang semakin ketat, hal tersebut mengharuskan Seniman Coffee Studio dapat memenuhi kepuasan konsumen. Kepuasan yang dimaksud agar konsumen lebih setia dan terus melakukan pembelian diharapkan menarik konsumen baru untuk berkunjung, maka perlu diadakan penelitian tentang "Pengaruh Store Atmosphere, Kualitas Produk, dan Kualitas Layanan terhadap Kepuasan Konsumen di Seniman Coffee Studio".

\subsection{Tujuan}

Tujuan dari penelitian ini yaitu sebagai berikut.

1. Menganalisis pengaruh store atmosphere terhadap kepuasan konsumen di Seniman Coffee Studio.

2. Menganalisis pengaruh kualitas produk terhadap kepuasan konsumen di Seniman Coffee Studio.

3. Menganalisis pengaruh kualitas layanan terhadap kepuasan konsumen di Seniman Coffee Studio.

\section{Metode Penelitian}

\subsection{Lokasi dan Waktu Penelitian}

Lokasi penelitian dilaksanakan di Seniman Coffee Studio yang terletak di jalan Sriwedari Kecamatan Ubud, Kabupaten Gianyar, Provinsi Bali. Penelitian ini dilakukan pada bulan Maret sampai April 2018. Pemilihan lokasi penelitian ditentukan dengan metode purposive yaitu suatu teknik penentuan lokasi penelitian secara sengaja berdasarkan pertimbangan tertentu.

\subsection{Jenis dan Sumber Data}

Jenis data yang digunakan dalam penelitian ini dikelompokkan menjadi dua yaitu data kualitatif dan data kuantitatif. Pada penelitian ini data kualitatif yang dicari adalah sejarah dan gambaran umum, serta struktur organisasi Seniman Coffee Studio sedangkan data kuantitatif dalam penelitian ini yaitu data yang diisi oleh pengunjung 
Seniman Coffee Studio melalui kuesioner. Sumber data dalam penelitian ini yaitu data primer dan data sekunder. Data primer adalah sumber data yang diperoleh langsung dari responden melalui penyebaran kuisioner di Seniman Coffee Studio. Data sekunder mencakup data yang diperoleh melalui data yang telah diteliti dan dikumpulkan oleh pihak lain yang berkaitan dengan permasalahan penelitian.

\subsection{Metode Pengumpulan Data}

Metode pengumpulan data dalam penelitian ini menggunakan metode kuesioner, wawancara, dan observasi.

\subsection{Populasi dan Sampel Penelitian}

Populasi dalam penelitian ini adalah responden yang berkunjung dan sedang menikmati kopi di Seniman Coffee Studio. Metode pengambilan sampel yang digunakan adalah accidental sampling yaitu teknik pengambilan sampel secara kebetulan. Penentuan jumlah sampel dalam penelitian ini secara quota sampling yaitu sejumlah 50 orang responden.

\subsection{Variabel dan Pengukuran}

Variabel-variabel yang akan dianalisis dalam penelitian ini adalah store atmosphere, kualitas produk, kualitas layanan dan kepuasan konsumen. Pada pelaksanaan penelitian ini, peneliti memberikan skala untuk mengukur variabel-variabel yang akan diteliti melalui anggaran responden dengan menggunakan skala likert.

\subsection{Model Penelitian}

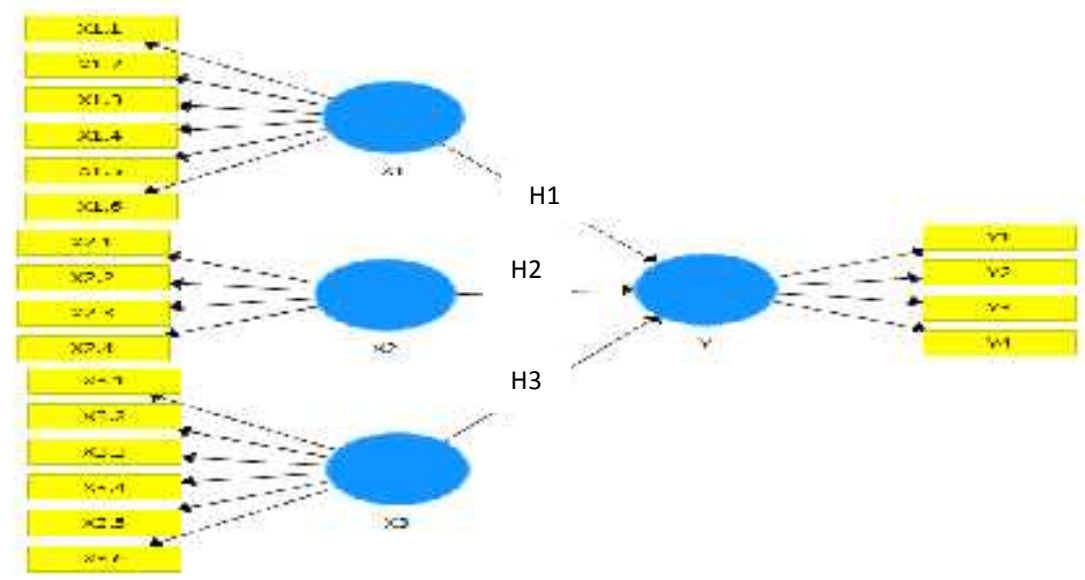

\subsection{Metode Analisis Data}

Gambar 1. Model Penelitian

Pengujian hipotesis penelitian dilakukan dengan menggunakan model persamaan struktural (Structural Equation Modeling - SEM) berbasis variance yang terkenal disebut Partial Least Square (PLS). PLS merupakan metode analisis yang powerfull, karena tidak mengasumsikan data harus dengan pengukuran skala tertentu, jumlah sampel kecil, dan dapat digunakan untuk konfirmasi teori (Ghozali, 2014). Alat bantu yang digunakan dalam penelitian ini berupa program Smart PLS Versi 3.0. 


\section{Hasil dan Pembahasan}

\subsection{Karakteristik responden}

Berdasarkan hasil penyebaran kuesioner responden dalam penelitian ini terdapat 56\% laki-laki dan $44 \%$ perempuan. Pengunjung sebagian besar masih memiliki usia produktif dengan kelompok umur 15-64 tahun yang sebagian besar berasal dari luar negeri. Responden dalam penelitian ini lebih banyak memiliki pekerjaan sebagai pegawai swasta. Pengunjung yang datang sebagian besar bersama teman, dan informasi yang didapat pengunjung mengenai Seniman Coffee Studio diperoleh dari teman dengan rata-rata sudah berkunjung lebih dari 2 kali.

\subsection{Analisis Konfirmatif}

Hasil calculate akhir dengan melakukan pengedropan pada 3 indikator menunjukkan bahwa terdapat 17 indikator yang memiliki nilai outer loading lebih dari 0,7 sehingga model persamaan struktural yang dikembangkan pada penelitian ini dapat dilihat pada gambar 2 sebagai berikut:

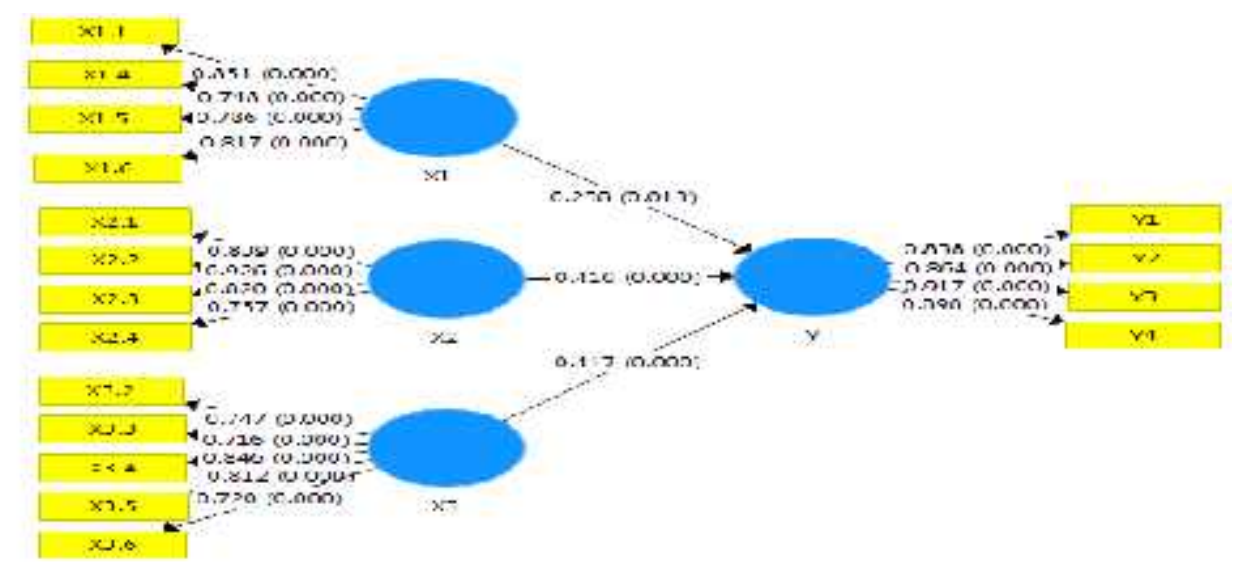

Gambar 2. Output Model Persamaan Struktural berbasis Smart PLS 3.0

\subsubsection{Hasil Analisis Model Pengukuran (Outer/Mmeasurement Model)}

Analisis pada outer model menitikberatkan pada pemeriksaan hubungan variabel laten dengan indikator-indikatornya. Mengingat terdapat empat variabel dengan masingmasing variabel diukur melalui indikator-indikator reflektif, maka terdapat empat jenis analisis pengukuran seperti diperlihatkan pada tabel-tabel berikut:

a. Hasil Uji Model Pengukuran pada Variabel Store Atmosphere

Output model pengukuran pada variabel store atmosphere yang direfleksikan oleh 4 (empat) indikator dapat dilihat pada tabel 1. 
Tabel 1 .

Uji Model Pengukuran dari store atmosphere

\begin{tabular}{|c|c|c|c|c|c|}
\hline \multirow{2}{*}{$\begin{array}{l}\text { Kode } \\
\text { X1.1 }\end{array}$} & \multirow{2}{*}{$\begin{array}{c}\text { Pernyataan } \\
\text { Gaya arsitektur bangunan }\end{array}$} & \multirow{2}{*}{$\begin{array}{c}\text { Outer } \\
\text { Loading } \\
0,851\end{array}$} & \multirow{2}{*}{$\begin{array}{c}\text { Standard } \\
\text { Error }\end{array}$} & \multicolumn{2}{|c|}{ T-Statistics } \\
\hline & & & & 19,2007 & $* *$ \\
\hline X1.4 & Ruang gerak leluasa & 0,748 & 0,0784 & 9,5456 & $* *$ \\
\hline $\mathrm{X} 1.5$ & Penempatan kasir & 0,786 & 0,0846 & 9,2955 & $* *$ \\
\hline X1.6 & Penanda di kedai & 0,817 & 0,0726 & 11,2487 & $* *$ \\
\hline
\end{tabular}

Keterangan :

Tanda ** menyatakan signifikan

Sumber : Diolah dari data primer, 2018

Tabel 1 menunjukkan bahwa indikator gaya arsitektur bangunan (X1.1) dengan nilai loading terbesar. Hal ini mengindikasikan gaya arsitektur atau desain bangunan yang dimiliki oleh Seniman Coffee Studio merupakan penentu utama dari store atmosphere ketika konsumen memutuskan untuk berkunjung ke Seniman Coffee Studio. Terlihat pula, indikator ruang gerak leluasa (X1.4) memiliki nilai loading terkecil. Hal ini mengindikasikan ruang gerak leluasa di Seniman Coffee Studio sangat perlu ditingkatkan, agar konsumen merasa lebih nyaman ketika berada dalam kedai.

b. Hasil Uji Model Pengukuran untuk Variabel Kualitas Produk

Output model pengukuran pada variabel kualiats produk yang direfleksikan oleh 4 (empat) indikator dapat dilihat pada tabel 2.

Tabel 2.

Uji Model Pengukuran dari Kualitas Produk

\begin{tabular}{llccrl}
\hline Kode & \multicolumn{1}{c}{ Pernyataan } & $\begin{array}{c}\text { Outer } \\
\text { Loading }\end{array}$ & $\begin{array}{c}\text { Standard } \\
\text { Error }\end{array}$ & T-Statistics \\
\hline X2.1 & Kualitas kopi & 0,839 & 0,0452 & 18,5661 & $* *$ \\
X2.2 & Aroma kopi & 0,926 & 0,0252 & 36,7508 & $* *$ \\
X2.3 & Penyajian kopi & 0,820 & 0,0503 & 16,3264 & $* *$ \\
X2.4 & Informasi produk kopi & 0,757 & 0,0780 & 9,7096 & $* *$ \\
\hline
\end{tabular}

Keterangan :

Tanda ** menyatakan signifikan

Sumber : Diolah dari data primer, 2018

Tabel 2 menunjukkan indikator aroma kopi (X2.2) dan indikator informasi produk (X2.4) memiliki nilai loading terbesar dan terkecil sebagai refleksi kualitas produk di Seniman Coffee Studio. Aroma kopi merupakan refleksi utama sebagai ciri khas dari kualitas produk yang dimiliki oleh Seniman Coffee Studio. Informasi produk dengan nilai loading terendah sangat perlu dicermati kemampuan indikator ini, dibandingkan dengan 2 indikator lainnya.

c. Hasil Uji Model Pengukuran untuk Variabel Kualitas Layanan

Output model pengukuran pada variabel kualitas layanan yang direfleksikan oleh 5 (lima) indikator dapat dilihat pada tabel 3. 
Tabel 3.

Uji Model Pengukuran dari Kualitas Layanan

\begin{tabular}{llccr}
\hline Kode & Pernyataan & $\begin{array}{c}\text { Outer } \\
\text { Loading }\end{array}$ & $\begin{array}{c}\text { Standard } \\
\text { Error }\end{array}$ & T-Statistics \\
\hline X3.2 & Ketepatan penanganan konsumen & 0,747 & 0,0850 & $8,7877 * *$ \\
X3.3 & Pelayanan cepat dan tanggap & 0,716 & 0,1164 & $6,1501 * *$ \\
X3.4 & $\begin{array}{l}\text { Karyawan memiliki pengetahuan } \\
\text { produk yang cukup }\end{array}$ & 0,846 & 0,0520 & $16,2801 * *$ \\
X3.5 & $\begin{array}{l}\text { Karyawan memiliki sopan } \\
\text { santun }\end{array}$ & 0,812 & 0,0657 & $12,3613 * *$ \\
X3.6 & $\begin{array}{l}\text { Pelayanan tanpa memandang } \\
\text { status sosial }\end{array}$ & 0,720 & 0,1019 & $7,0686 * *$ \\
\hline
\end{tabular}

Keterangan :

Tanda $* *$ menyatakan signifikan

Sumber : Diolah dari data primer, 2018

Hasil model pengukuran variabel kualitas layanan seperti terlihat pada tabel.3 menunjukkan indikator karyawan memiliki pengetahuan produk yang cukup (X3.4) dengan nilai loading terbesar. Hal tersebut mengindikasikan semua karyawan Seniman Cofee Studio mengetahui semua jenis dan deskripsi dari produk yang ditawarkan sedangkan pelayanan cepat dan tanggap memiliki nilai loading terendah sebagai refleksi dari variabel kualitas layanan, sehingga perlu ditingkatkan.

d. Hasil Uji Model Pengukuran untuk Variabel Kepuasan Konsumen

Output model pengukuran pada variabel kepuasan konsumen yang direfleksikan oleh 4 (empat) indikator dapat dilihat pada tabel 4.

Tabel 4.

Uji Model Pengukuran dari Kepuasan Konsumen

\begin{tabular}{llccc}
\hline Kode & Pernyataan & $\begin{array}{c}\text { Outer } \\
\text { Loading }\end{array}$ & $\begin{array}{c}\text { Standard } \\
\text { Error }\end{array}$ & T-Statistics \\
\hline Y1 & Kepuasan store atmosphere & 0,838 & 0,0658 & $12,7288 * *$ \\
Y2 & Kepuasan kualitas produk & 0,864 & 0,0454 & $19,0371 * *$ \\
Y3 & Kepuasan kualitas layanan & 0,917 & 0,0225 & $40,7499 * *$ \\
Y4 & Kepuasan secara & 0,898 & 0,0324 & $27,7385 * *$ \\
& keselurahan & & & \\
\hline
\end{tabular}

Keterangan :

Tanda $* *$ menyatakan signifikan

Sumber : Diolah dari data primer, 2018

Tabel 4 memperlihatkan seluruh indikator reflektif dari kepuasan konsumen memiliki nilai loading berkisar 0,838 hingga 0,917. Indikator kepuasan kualitas layanan (Y3) yang menyatakan kepuasan konsumen dari kualitas layanan yang diberikan di Seniman Coffee Studio yang memiliki nilai loading tertinggi merupakan refleksi terbesar variabel ini, sedangkan indikator kepuasan store atmosphere (Y1) merupakan refleksi terkecil dari variabel kepuasan konsumen. Mengacu pada nilai loading indikator kepuasan store atmosphere paling rendah maka harus lebih ditingkatkan, agar konsumen merasa puas dengan keseluruhan yang ditawarkan oleh Seniman Coffee Studio. 


\subsubsection{Model Struktural (Inner Model)}

Model struktural atau inner model adalah model yang menggambarkan signifikansi hubungan dan pengaruh antar variabel laten, yaitu store atmosphere, kualitas produk dan kualitas layanan terhadap kepuasan konsumen. Hubungan kausal yang terbentuk umumnya dinyatakan dalam beberapa hipotesis yang dikembangkan peneliti. Pada penelitian ini terdapat 3 hipotesis, hasil pengujian koefisien jalur (path coefficient) antara variabel laten eksogen dengan variabel laten endogen dan pengujian hipotesis diperlihatkan pada tabel 5. Proses untuk mendapatkan inner model dilakukan melalui teknik bootstrapping dengan Smart PLS versi 3.

Tabel 5.

Uji Model Struktural dan Hipotesis yang Dibangun

\begin{tabular}{clccccc}
\hline $\begin{array}{c}\text { Hipo- } \\
\text { tesis }\end{array}$ & $\begin{array}{l}\text { Variabel } \\
\text { Eksogenus }\end{array}$ & $\begin{array}{c}\text { Variabel } \\
\text { Endogenus }\end{array}$ & $\begin{array}{r}\text { Original } \\
\text { Sample }\end{array}$ & $\begin{array}{c}\text { Standard } \\
\text { Error }\end{array}$ & T statistic & P Value \\
\hline $\mathrm{H}_{1}$ & $\begin{array}{l}\text { Store } \\
\text { Atmosphere }\end{array}$ & $\begin{array}{c}\Rightarrow \text { Kepuasan } \\
\text { Konsumen }\end{array}$ & 0,238 & 0,092 & 2,4953 & 0,013 \\
\hline $\mathrm{H}_{2}$ & $\begin{array}{l}\text { Kualitas } \\
\text { Produk }\end{array}$ & $\begin{array}{c}\Rightarrow \text { Kepuasan } \\
\text { Konsumen }\end{array}$ & 0,410 & 0,117 & 3,5000 & 0,000 \\
\hline $\mathrm{H}_{3}$ & $\begin{array}{l}\text { Kualitas } \\
\text { Layanan }\end{array}$ & $\begin{array}{c}\Rightarrow \text { Kepuasan } \\
\text { Konsumen }\end{array}$ & 0,417 & 0,109 & 3,8226 & 0,000 \\
\hline
\end{tabular}

Sumber : Diolah dari data primer, 2018

Memperhatikan tabel 5 maka secara jelas ketiga hipotesis yang dikembangkan didukung secara nyata oleh hasil dari analisis model struktural yang dilakukan. Hasil pengaruh langsung variabel eksogen terhadap variabel endogen dengan taraf signifikan $5 \%(0,05)$ maka Ho ditolak jika nilai $\mathrm{P}$-value $<0,05$ maka hasil penelitian secara statistik adalah signifikan dapat dijelaskan sebagai berikut.

1. Store atmosphere berpengaruh langsung terhadap kepuasan konsumen dengan koefisien jalur 0,238 sudah signifikan dengan p-value sebesar $(0,013)$ dan memiliki original sampel bernilai positif, maka Ho ditolak yang berarti H1 diterima.

2. Kualitas produk berpengaruh langsung terhadap kepuasan konsumen dengan koefisien jalur 0,410 sudah signifikan dengan p-value sebesar $(0,000)$ dan memiliki original sampel bernilai positif, maka Ho ditolak yang berarti H2 diterima.

3. Kualitas layanan berpengaruh langsung terhadap kepuasan konsumen dengan koefisien jalur 0,417 sudah signifikan dengan p-value sebesar $(0,000)$ dan memiliki original sampel bernilai positif, maka Ho ditolak yang berarti H3 diterima.

Sebelum dilakukan interpretasi terhadap hasil analisis model persamaan struktural penelitian ini, beberapa peneliti (Fornell \& Larcker, 1981; Chin et al., 2003; Hair et al., 2012; Henseler et al., (2009 dalam Suryawardani, 2018) merekomendasikan agar kelayakan model diperiksa. Tabel 6 memperlihatkan ukuran-ukuran yang lazim 
digunakan untuk menilai kelayakan model persamaan struktural yang dianalisis dengan metode Smart PLS:

Tabel 6.

Uji Kelayakan Model Pengukuran Struktural

\begin{tabular}{lccccc}
\hline \multicolumn{1}{c}{$\begin{array}{c}\text { Variabel } \\
\text { Laten }\end{array}$} & $\begin{array}{c}\text { Jenis } \\
\text { Variabel }\end{array}$ & $\begin{array}{c}\text { Jumlah } \\
\text { Indikator }\end{array}$ & $\begin{array}{c}\text { Composite } \\
\text { Reliability } \\
\text { (CR) }\end{array}$ & $\begin{array}{c}\text { Average } \\
\text { Variance } \\
\text { Extracted } \\
\text { (AVE) }\end{array}$ & $\mathrm{R}^{2}$ \\
\hline $\begin{array}{l}\text { Store } \\
\text { Atmosphere }\end{array}$ & Eksogenus & 4 & 0,877 & 0,642 & $\mathrm{NA}^{\mathrm{a}}$ \\
\hline $\begin{array}{l}\text { Kualitas } \\
\text { produk }\end{array}$ & Eksogenus & 4 & 0,904 & 0,702 & $\mathrm{NA}^{\mathrm{a}}$ \\
\hline $\begin{array}{l}\text { Kualiats } \\
\text { Layanan }\end{array}$ & Eksogenus & 5 & 0,879 & 0,593 & $\mathrm{NA}^{\mathrm{a}}$ \\
\hline $\begin{array}{l}\text { Kepuasan } \\
\text { Konsumen }\end{array}$ & Endogenus & 4 & 0,932 & 0,774 & 0,712 \\
\hline Rata-rata & & - & - & $0,677^{\mathrm{b}}$ & \\
\hline
\end{tabular}

Keterangan :

a Nilai tidak tersedia karena laten berjenis eksogenus

${ }^{\mathrm{b}}$ : Rataan terbobot dengan bobot adalah jumlah indikator

Sumber : Diolah dari data primer, 2018

Tabel 6 terlihat nilai koefisien determinasi $\left(\mathrm{R}^{2}\right)$ untuk variabel endogen. Merujuk Chin et al. (1998) dalam Ghozali 2014, variabel laten endogen dengan nilai $\mathrm{R}^{2}$ berada pada rentang nilai 0,19 hingga 0,33 dikategorikan variabel yang dijelaskan secara lemah (weakly explained); berada pada rentang 0,33 hingga 0,67 dikategorikan variabel yang dijelaskan secara moderat; dan di atas nilai 0,67 dikategorikan terjelaskan secara kuat (substantially explained). Pada penelitian ini kepuasan konsumen merupakan variabel endogen yang terjelaskan secara kuat yaitu sebesar 0,712 oleh variabel-variabel eksogen yang bersesuaian, artinya kemampuan variabel eksogen store atmosphere, kualitas produk, dan kualitas layanan dalam menjelaskan keragaman dari kepuasan konsumen sebesar $71,2 \%$.

\subsection{Model Fit}

Menilai kelayakan model persamaan struktural secara utuh, maka nilai Goodness of Fit (GoF) dari model bisa dilakukan dengan merujuk formula yang diperkenalkan oleh Tenenhaus et al. (2005, dalam Suryawardani, 2018) sebagai berikut:

$$
\mathrm{GoF}=\sqrt{\overline{\text { Communality }} \times \overline{\overline{R^{2}}}}=\sqrt{\overline{\overline{A V E}} \times \overline{R^{2}}}
$$

Persamaan di atas, $\overline{\mathrm{AVE}}$ merupakan nilai rataan terbobot dengan bobot diperoleh dari jumlah indikator untuk setiap variabel laten. Menggunakan formula ini, maka GoF dari model dihitung sebesar 0.5858, sebuah ukuran yang melebihi nilai ambang 0.50 untuk menyatakan model bisa diterima dan diintepretasikan, dengan demikian, interpretasi analisis bisa dilanjutkan.

Mengacu pada hasil analisis, nilai SRMR (Standardized Root Mean Residual) yaitu 0,1 menunjukkan bahwa model dikatakakan layak karena jika nilainya > dari 0,15 
maka artinya model tidak layak. Nilai NFI (Normed Fit Index) nilainya sebesar 0,65 mengindikasikan model yang baik, karena nilai NFI memiliki rentang lebih dari 0,5 dikatakan layak. Dari hasil nilai SRMR dan NFI maka dapat dikatakan model dalam penelitian ini sudah fit.

\section{Simpulan dan Saran}

\subsubsection{Simpulan}

Berdasarkan hasil penelitian yang telah dilakukan dalam penelitian ini, maka dapat disimpulkan sebagai berikut.

1) Store atmosphere berpengaruh signifikan dan memiliki nilai positif terhadap kepuasan konsumen sebesar 0,238 dengan p-value $(0,013)$. Store atmosphere direfleksikan oleh empat indikator yaitu gaya arsitektur bangunan, ruang gerak leluasa, penempatan kasir dan penanda di kedai.

2) Kualitas produk berpengaruh signifikan dan memiliki nilai positif terhadap kepuasan konsumen sebesar 0,410 dengan p-value $(0,000)$. Kualitas produk direfleksikan oleh empat indikator yaitu indikator kualitas kopi, aroma kopi, penyajian kopi dan informasi produk,

3) Kualitas layanan berpengaruh signifikan dan memiliki nilai positif terhadap kepuasan konsumen sebesar 0,417 dengan p-value (0,000). Kualiats layanan direfleksikan oleh lima indikator yaitu ketepatan penanganan konsumen, pelayanan cepat dan tanggap, karyawan memiliki pengetahuan produk yang cukup, karyawan memiliki sopan santun, dan pelayanan tanpa memandang status sosial.

\subsection{Saran}

Berdasarkan hasil penelitian, store atmosphere, kualitas produk, dan kualitas layanan memiliki pengaruh secara signifikan terhadap kepuasan konsumen. Store atmosphere memiliki pengaruh yang terkecil dari variabel eksogen lainnya, dalam hal ini perlu dicermati dan menjadi perhatian lebih bagi Seniman Coffee Studio untuk dapat meningkatkan kepuasan konsumen, sehingga menjadi nilai tambah dan ketertarikan konsumen untuk berkunjung ke Seniman Coffee Studio meningkat.

\section{Ucapan Terima Kasih}

Penulis mengucapkan terima kasih kepada pihak yang telah mendukung terlaksananya penelitian ini yaitu kepada manajer dan pegawai Seniman Coffee Studio dan seluruh konsumen yang telah bersedia menjadi responden dalam penelitian ini. Ucapan terimakasih juga disampaikan kepada keluarga, teman-teman dan semua pihak yang tidak dapat disebutkan satu persatu. Semoga penelitian ini bermanfaat sebagaimana mestinya.

\section{Daftar Pustaka}

Berman B, Evans J. 2001. Retail Management: A Strategic to Approach. New Jersey (US): Prentice Hall.

Diwangkoro, E, 2016. Tingkat Kepuasan Konsumen Terhadap Kualitas Kopi dan Kualitas Pelayanan di Café Kopi Garasi Candi Winangun Ngaglik Sleman Yogyakarta. Skripsi tidak diterbitkan. Yogyakarta:Universitas Negeri 
E-Jurnal Agribisnis dan Agrowisata ISSN:2301-65 Vol. 8, No. 1, Januari 2019

Yogyakarta (internet) (diakses pada tanggal 12 Desember 2017) tersedia dalam http://eprints.uny.ac.id/44479/1/09\%20ELAN\%20.pdf

Fajriah, S. 2015. Pengaruh Store Atmosphere dan Dimensi Kualitas Produk Terhadap Kepuasan Konsumen di Waroeng Taman Bogor. Skripsi tidak diterbitkan. Bogor: Institut Pertanian Bogor (internet) (diakses pada tanggal 12 Desember 2017) tersedia dalam http://repository.ipb.ac.id/handle/123456789/80741

Ghozali I. 2014. Partial Least Square Konsep, Teknik, dan Aplikasi Menggunakan Program SmartPLS 3.0. Semarang : Badan Penerbit

Kotler, Philip. 2002. Manajemen Pemasaran.Edisi Milinium 1. Jakarta: Prehanllindo

Mangkunegara, A. A. A. Prabu.2002.Perilaku Konsumen.Bandung: PT Refika Aditama

Pusat Data dan Sistem Informasi Pertanian Sekretariat Jenderal - Kementrian Pertanian. 2016. Outlook Kopi Komuditas Pertanian Subsektor Perkebunanhttp://epublikasi.setjen.pertanian.go.id/epublikasi/outlook/2016/Per kebunan/OUTLOOK\%20KOPI\%202016/files/assets/common/downloads/OUT LOOK\%20KOPI\%202016.pdf (diakses pada tanggal 12 Desember 2017)

Sunyoto, D.2013.Metode dan Instrumen Penelitian Ekonomi dan Bisnis.Jakarta: PT Buku Seru

Sugiyono.2015. Metode Penelitian Manajemen. Bandung: Alfabeta

Supranto.2011. Pengukuran Tingkat Kepuasan Pelanggan. Jakarta: PT Rineka Cipta

Suryawardani, I.G.A.O. 2018. Evaluation of Marketing Strategy if Sanur Village Festival Based on Visitors Behavior. Internasional Journal of Applied Business and Economic Research. Vol. 16, Number 2, 2018. Page:261-276. ISSN:097273012

Tjiptono, Fandy. 1997. Strategi Pemasaran. Yogyakarta: Andi

Wiranatha, A.S., I G.A.O. Suryawardani, and 1 K.G.Bendesa. 2018. Model of Foreign Tourist' Loyalty in Cultural and Heritage Tourism. Journal of Global Stochastics Analysis.

Wiranatha, A.S., and I G.A.O. Suryawardani. 2018. A Structural Model of Community Based Agrotourism Development at The World Heritage Site of Jatiluwih Rice Field Terrace in Tabanan, Bali. Journal of Global Stochastics Analysis, Vol. 5 Number 7 (2018), page; 65-81. ISSN: 2248-94444. 